\title{
Implementação de contextos telecolaborativos de aprendizagem de línguas: $o$ caso Teletandem
}

\author{
Daniela Nogueira de Moraes Garcia \\ Universidade Estadual Paulista (UNESP), Assis, São Paulo, Brasil \\ dani7garcia@gmail.com \\ http://orcid.org/0000-0003-2813-7538
}

Micheli Gomes de Souza

Universidade Estadual do Norte do Paraná (UENP), Jacarezinho, Paraná, Brasil souzagomes.micheli@gmail.com https://orcid.org/0000-0003-3111-9613

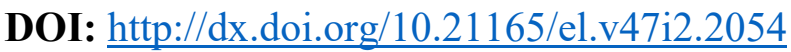

\begin{abstract}
Resumo
Novos contextos e perspectivas se agigantam no cenário educacional com o desenvolvimento de ferramentas tecnológicas digitais. $\mathrm{O}$ acesso aos povos constitui-se uma vertente importante na reconfiguração de práticas pedagógicas, currículos de cursos e contextos de formação de professores. Nesse cenário, o projeto Teletandem Brasil (TELLES, 2006) tem aberto portas à comunicação intercultural e experiências singulares para aprendizes de português de universidades estrangeiras e aprendizes de línguas estrangeiras vinculados à UNESP. Tendo em vista os contextos de telecolaboração para a promoção de transformações nos processos de ensino e aprendizagem de línguas, o objetivo deste artigo é delinear (a) um panorama histórico da implementação do Teletandem, (b) apresentar o embasamento teórico e princípios que caracterizam o contexto Teletandem e (c) apresentar perspectivas de pesquisa no campo da telecolaboração.
\end{abstract}

Palavras-chave: línguas estrangeiras; formação de professores; telecolaboração.

\section{Technologies and the intercultural communication in foreign language teaching/learning and teachers' education}

\begin{abstract}
New contexts and perspectives have become gigantic in the educational scenery due to the development of digital technological tools. The access to people constitutes an important dimension in reconfiguration pedagogical practices, curriculum of courses and contexts of teachers' development. In this scenery, the project Teletandem Brasil (TELLES, 2006) has opened doors for intercultural communication and singular experiences for Portuguese learners from foreign universities and foreign language learners from UNESP. Considering the contexts of telecollaboration for the promotion of changes regarding processes of languages teaching and learning, the goal of this article is to outline (a) a historical overview of the implementation of Teletandem, (b) to present the theoretical base and principles of Teletandem, (c) to present research perspectives in the field of telecollaboration.
\end{abstract}

Keywords: foreign languages; teachers' development; telecollaboration. 


\section{Introdução}

Com a emergência das novas mídias digitais, ferramentas e ambientes, notamos a constante necessidade de se repensar o cenário de ensino/aprendizagem de línguas estrangeiras e a formação de professores. Reconhecemos a grande demanda por, nas palavras de Clandin e Hadfield (2016, p. 10), "cidadãos engajados e profissionais produtivos em nosso mundo digitalmente enredado". Além disso, destacamos a necessidade de formação de cidadãos críticos e atuantes na desconstrução de discursos preconceituosos e essencialistas, cada vez mais propagados em ambientes digitais de comunicação.

Mediante dificuldades geográficas, linguísticas e econômicas, as tecnologias maximizaram perspectivas de acesso aos povos, línguas e culturas e proporcionaram novos contextos pedagógicos que perpassam o uso real da língua, o desenvolvimento de uma postura crítico-reflexiva, a vivência da autonomia e a construção de conhecimento de forma bastante plural. Dessa forma, a telecolaboração e a comunicação intercultural têm despontado como grandes aliadas às práticas pedagógicas e de formação ao permitirem ambientes muito profícuos de trocas linguísticas e culturais.

O presente trabalho irá enfocar o Teletandem como um contexto de telecolaboração com vistas ao seu potencial de transformar as relações de ensino/aprendizagem nas línguas. Assim, iniciamos com um percurso histórico de implementação do Projeto Teletandem Brasil (TTB) para, em seguida, abordar seu embasamento teórico e princípios. Apresentamos perspectivas de pesquisa na área e tecemos algumas considerações, ao final.

\section{Da aprendizagem em Tandem ao Teletandem}

As ações pedagógicas em tandem datam da década de 60 na Europa (VASSALLO; TELLES, 2006). Trata-se de "uma forma aberta de aprendizagem que envolve dois aprendizes de línguas nativas diferentes que trabalham juntos no intuito de aprender a língua do outro" (LITTLE et al., 1999, p. 1, tradução nossa). Atualmente, a centralidade dada ao falante nativo nessa definição é ampliada para incluir falantes proficientes em diferentes línguas. Assim, no contexto Teletandem, entende-se que não é necessário ser falante nativo para estabelecer uma parceria de aprendizagem de línguas, mas ser proficiente na língua alvo do par interagente.

Vassallo e Telles (2008) reconhecem o desejo de compartilhar a ideia de um trabalho em pares, recíproco, autônomo e colaborativo e, ainda, um revezamento de papéis de aprendiz e de falante competente como as principais características da aprendizagem em tandem. A flexibilidade das ações em tandem é destacada também pelos autores como uma de suas principais vantagens. Os princípios que orientam a prática de tandem, autonomia, reciprocidade e uso separado das línguas, ampliam as possibilidades de exercício colaborativo e de desenvolvimento linguístico para os pares interagentes.

Considerando que o tandem se difere de meros encontros entre estrangeiros, seus princípios auxiliam os pares interagentes a estabelecer propósitos compartilhados para as interações. Schwienhorst (1998) aponta a reciprocidade, a autonomia e o uso 
separado de línguas como pilares para a aprendizagem em tandem, como ilustra a figura.

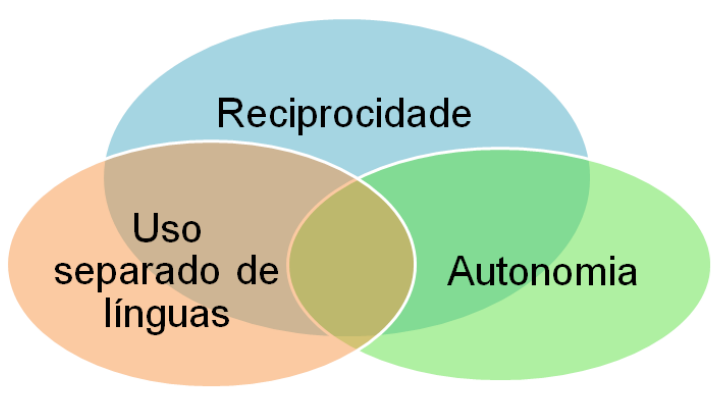

Figura 1. Princípios Tandem e Teletandem

Como podemos observar, os princípios se interconectam. É esperado dos interagentes um comprometimento e igualdade nas ações de forma que ambos parceiros se beneficiem, com equidade das ações, e caminhem rumo a posturas autônomas, com auxílio do par.

De acordo com Little (2002), os aprendizes in-tandem são autônomos no sentido em que são os responsáveis pela gestão da sua própria aprendizagem. Ao mesmo tempo, a aprendizagem em parceria é recíproca no sentido em que se baseia num compromisso mútuo.

Para Vassallo e Telles (2006), a não mistura de línguas é pensada para que se evite, ainda que involuntária, a predominância do par mais proficiente na sessão. Dessa maneira, ainda tende-se a garantir que o mesmo tempo esteja presente para cada uma das línguas.

Ainda pensando na distinção entre o Teletandem e meros encontros on-line entre estrangeiros, há um duplo enfoque previsto nas sessões de interação, no qual os parceiros deveriam desenvolver a habilidade de, enquanto interagem, devotar a mesma atenção ao conteúdo e à forma, como podemos observar abaixo. Não é apenas o assunto abordado, mas também a maneira pela qual o parceiro se expressa que difere o teletandem de um bate-papo na internet sob a teoria da Abordagem lexical e Enfoque na Forma (LEWIS, 1993; DOUGHTY; WILLIAMS, 2004).

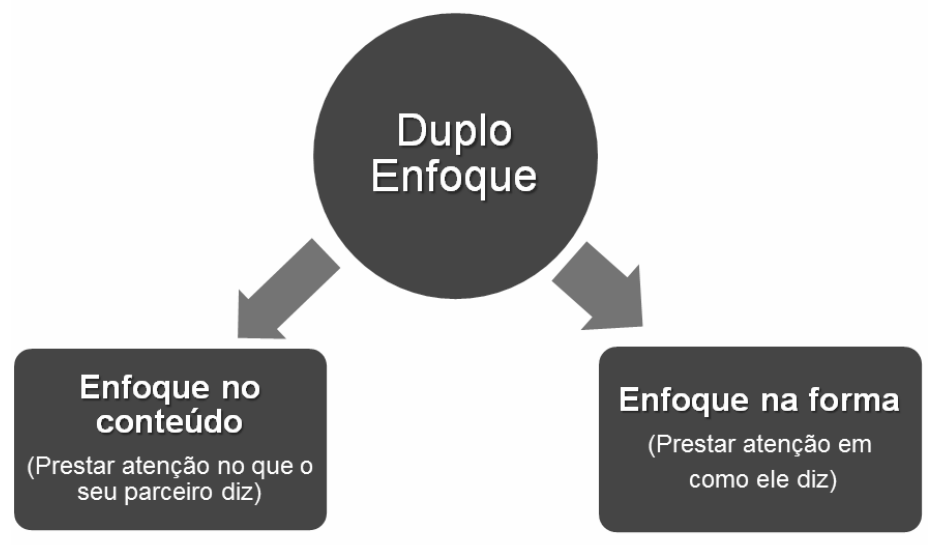

Figura 2. Duplo enfoque 
Inspirado na aprendizagem em tandem, o Teletandem é pensado a partir de demandas identificadas em cenário educacional brasileiro como a dificuldade de acesso aos falantes nativos ou proficientes e barreiras geográficas e financeiras. Telles (2006), a partir de experiências pessoais em tandem, contempla o potencial das tecnologias no encurtamento de barreiras de tempo e espaço e propõe o Teletandem como "um contexto virtual, autônomo e colaborativo no qual dois falantes de línguas diferentes utilizam recursos de tecnologia VOIP (texto, voz e imagem de webcam) para ajudar o parceiro a aprender a sua língua materna (ou linguagem de proficiência)" (TELLES, 2015, p. 364).

\section{Um pouco da trajetória: passos da implementação}

Em 2004, pensamentos e passos iniciais podiam ser notados rumo à telecolaboração na UNESP, campus de Assis. Sob uma proposta ainda não bem delineada, mas um desejo grande pelo contato intercultural, estudantes brasileiros de Língua Inglesa do curso de Letras frequentavam lan houses ou, poucos, utilizavam computadores próprios para interações com estudantes estrangeiros, aprendizes de português. Um tímido acompanhamento era realizado por poucos professores que também auxiliavam na formação de parcerias.

Destacamos algumas questões que marcaram o início do Teletandem, a saber: (a) o pouco envolvimento/conhecimento de professores e departamentos de Língua Portuguesa das instituições estrangeiras; (b) a diferença de agendas entre alunos brasileiros (voluntários, extremamente motivados com o contato intercultural e desejosos pela aprendizagem de língua inglesa) e alunos estrangeiros (voluntários, aprendizes de língua portuguesa, com participação desvinculada de suas aulas); (c) impossibilidade de acompanhamento e eficaz suporte aos alunos dada a ausência de um laboratório equipado com recursos de áudio e vídeo para a prática de Teletandem dentro da universidade e (d) a escassez (com posterior evolução) dos aplicativos de mensagens instantâneas ao longo dos anos (MSN, Windows Live Messenger, ooVoo e, por fim, Skype - o mais utilizado em tempos atuais).

Em relação às parcerias iniciais, apoiávamo-nos nas indicações oferecidas pelos professores do exterior e o site do TTB. Não podemos deixar de mencionar a diferença na demanda. Garcia (2010, p. 113) ofereceu a seguinte descrição:

Ao se inscrever no website do TTB, inicialmente, o aluno fornece informações como nome, sobrenome, e-mail, universidade e curso que frequenta, ano, país em que reside, língua que quer aprender e língua materna, e horários disponíveis para praticar teletandem. Em seguida, preenche as lacunas com informações de cunho pedagógico, como o nível gramatical que possui da LE, o melhor nível de atuação, se escrito ou falado, na referida língua, os objetivos estabelecidos, quantidade de horas que irá dedicar ao teletandem e a duração desejada para parceria.

Em seguida, a Equipe TTB encarregava-se de um pareamento manual e enviava um e-mail com orientações aos parceiros, em inglês e português. O exercício da autonomia já se delineava nas primeiras parcerias. 
De 2007 em diante, o Projeto foi contemplado com fomento da FAPESP ${ }^{1}$ e, com isso, muitos outros ganhos foram advindos como visibilidade, laboratórios, visitas ao exterior, sistematização das pesquisas e produção científica, acompanhamento das interações, Teletandem em modalidade grupos, atualização de aplicativos e organização/logística aprimoradas.

\section{Teletandem: interação e mediação}

Como já afirmamos, o ano de 2007 foi um marco nas ações em Teletandem desenvolvidas na universidade.

A organização das sessões conta, desde então, com um trabalho colaborativo entre as instituições, brasileiras e do exterior, meses antes do início das parcerias. Por meio de documentos on-line, são trocadas informações acerca dos horários, dias, duração, fuso, número de participantes, de modo que, para o início das interações, todo o caminho previsível já esteja organizado.

A figura a seguir demonstra um tripé de ações que constituem a logística para efetivação de parcerias Teletandem.

$\begin{array}{lll}\text { Contato com Instituições Parceiras } & \text { Divulgação de Parcerias } & \text { Sessões de Teletandem } \\ \text { - Definição de calendário de } & \text { - Elaboração de formulários } & \text { - Mediação das interações } \\ \text { interações } & \text { de inscrição e listas de } & \text { - Gravação e coleta de dados } \\ \text { - Estabelecimento de acordos } & \text { presença } & \text { - Gerenciamento de } \\ \text { - Seleção e formação de } & \text { - Divulgação (via redes } & \text { equipamentos } \\ \text { mediadores } & \text { sociais e e-mail institucional) } & \text { - Gerenciamento de } \\ \text { - Definição de procedimentos } & \text { - Definição de critérios de } & \text { frequência e substituições de } \\ \text { pedagógicos } & \text { participação } & \text { inscritos } \\ \text { - Reserva de laboratórios de } & & \text { - Avaliação } \\ \text { informática } & & \text { - Emissão de declarações de } \\ \text { - Agendamento de interações } & \text { participação }\end{array}$

Figura 3. Logística Teletandem UNESP - Assis (SOUZA, 2016)

Considerando o grande número de ações descritas a partir do tripé "Contatos Divulgação - Sessões de Teletandem", reforçamos o trabalho colaborativo primoroso em cada uma das etapas, como se pode observar, desde a elaboração de "formulários de inscrição" e "avaliação" da experiência.

Desde 2008, as modalidades de parcerias têm sido diversificadas para atender o crescente número de grupos de instituições estrangeiras.

No Brasil, as parcerias podem ou não ser conduzidas em consonância com os currículos dos cursos de graduação dos alunos participantes. A modalidade de cada parceria é definida a partir das necessidades e acordos firmados entre as instituições participantes. Atualmente, as parcerias mais comuns são classificadas como a modalidade institucional integrada, na UNESP em São José do Rio Preto (CAVALARI; ARANHA, 2016) e institucional semi-integrada como na UNESP, em Assis.

\footnotetext{
${ }^{1}$ Projeto Temático FAPESP - Processo 2006/03204-2.
} 
O quadro seguinte apresenta as nomenclaturas utilizadas para caracterizar as principais modalidades de Teletandem, conforme os estudos e a literatura produzida a partir das experiências de estabelecimento de parcerias em contextos diversos.

Quadro 1. Síntese modalidades de teletandem, adaptado de Salomão (2006) (ZAKIR, 2015)

\begin{tabular}{|c|c|c|c|c|}
\hline \multicolumn{2}{|c|}{ (TELE)TANDEM NÃO-INSTITUCIONAL } & \multicolumn{3}{|c|}{ Não vinculado à instituição de nenhum dos participantes. } \\
\hline \multicolumn{2}{|c|}{ (TELE)TANDEM SEMI-INSTITUCIONAL } & \multicolumn{3}{|c|}{ É institucional somente para um dos dois participantes. } \\
\hline \multicolumn{2}{|c|}{ (TELE)TANDEM INSTITUCIONAL } & \multicolumn{3}{|c|}{$\begin{array}{l}\text { Realizado dentro de instituições como escolas, centros de línguas, faculdades e } \\
\text { universidades, que o reconhecem e o promovem. }\end{array}$} \\
\hline Integrado & Complementar & Opcional & Não-integrado & Semi-integrado \\
\hline $\begin{array}{l}\text { É reconhecido pela } \\
\text { instituição, faz parte } \\
\text { integrante do curso } \\
\text { e é obrigatório. } \\
\text { (BRAMMERTS et al. } \\
\text { 2002, p. 86) }\end{array}$ & $\begin{array}{l}\text { Pode ser escolhido } \\
\text { dentre as iniciativas } \\
\text { opcionais e, neste } \\
\text { caso, é reconhecido } \\
\text { pela instituição como } \\
\text { parte integrante do } \\
\text { curso. } \\
\text { (BRAMMERTS et al. } \\
\text { 2002, p. } 86 \text { ) }\end{array}$ & $\begin{array}{l}\text { Pode ser escolhido } \\
\text { dentre as iniciativas } \\
\text { opcionais, é } \\
\text { reconhecido pela } \\
\text { instituição, mas não é } \\
\text { considerado como parte } \\
\text { do curso. }\end{array}$ & $\begin{array}{l}\text { A instituição oferece apoio e/ou } \\
\text { alguns recursos (como meios } \\
\text { para encontrar um parceiro, } \\
\text { espaços, apoio técnico, serviço de } \\
\text { mediação), mas não há } \\
\text { reconhecimento oficial. Pode ser } \\
\text { desenvolvido sem que haja um } \\
\text { curso. (BRAMMERTS et al., 2002, } \\
\text { p. 84) }\end{array}$ & $\begin{array}{l}\text { Apenas uma das } \\
\text { instituições tem o } \\
\text { Teletandem como parte } \\
\text { integral do currículo e } \\
\text { atividade obrigatória, } \\
\text { enquanto a outra } \\
\text { reconhece o Teletandem } \\
\text { como atividade opcional. } \\
\text { (MESSIAS, mimeo) }\end{array}$ \\
\hline
\end{tabular}

A Figura 4 a seguir descreve uma sessão prototípica como, atualmente, conduzida na UNESP, Assis. Esclarecemos que o momento de feedback nem sempre se apresenta estruturado da forma como retrata a figura, podendo-se apresentar em diversos momentos da interação.

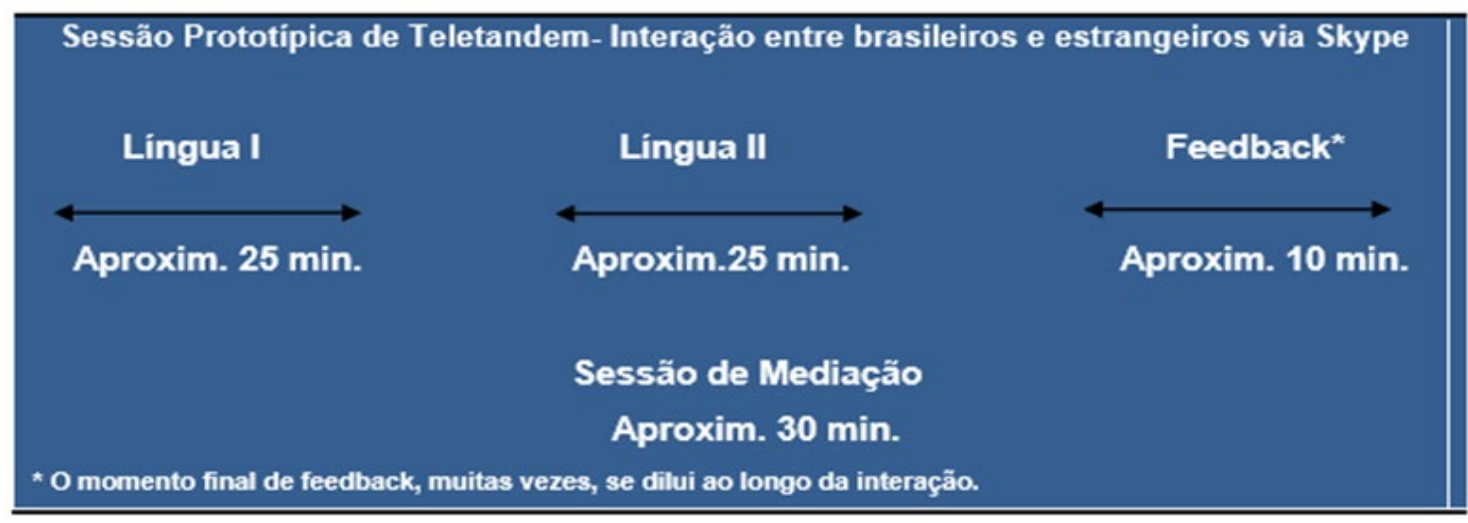

Figura 4. Partes de uma sessão de Teletandem prototípica

As sessões de mediação, também, puderam ser sistematizadas a partir do momento em que os grupos de estudantes se reuniam no Laboratório para suas interações.

A mediação, conforme Garcia (2017), constitui-se "uma sessão de reflexão oferecida após o término das interações em Teletandem, é conduzida por um professor/pesquisador/mediador e pode maximizar o processo" (SALOMÃO, 2008; FUNO, 2015). Para Brammerts e Calvert (2003), no aconselhamento, termo utilizado pelos autores, constam as ações de conhecimento oferecidas aos aprendizes, da responsabilidade de trabalhar de perto, em nível pessoal. Entendendo o aconselhamento como mediação no nosso contexto, identificamos o auxílio aos aprendizes de forma a assumir a responsabilidade e tomar decisões relacionadas às condições e necessidades 
individuais. As sessões de Mediação podem ser entendidas como: "encontros (a) presenciais ou virtuais, (b) em grupos (dos quais participam interagentes e mediadores) ou apenas entre um interagente e seu mediador, (c) previamente agendados ou solicitados sem agendamento prévio, (d) nos quais existe a intenção de prestar auxílio aos interagentes para que eles consigam alcançar seus objetivos de aprendizagem e oferecer o apoio necessário para que seus parceiros também alcancem os objetivos deles" (FUNO, 2015, p. 22).

A mediação é conduzida por alunos(as) de pós-graduação, professores(as), alunos(as) bolsistas de Iniciação Científica. Sugere-se que, ao menos, duas pessoas assumam as atividades de acompanhamento das interações e realização das mediações por grupo. As sessões têm a duração média de trinta minutos, como informa a figura, podendo ser conduzida de forma presencial ou on-line.

O tempo e os esforços da Equipe TTB foram assegurando ao projeto parcerias e ações mais sólidas, como se observa na trajetória descrita. $\mathrm{O}$ aumento no número de parcerias, consequentemente, gerou uma maior demanda por mediadores e, assim, o desafio por pessoas capacitadas para atuar no contexto. A formação de mediadores esteve sob estudos e, para isso, pensou-se no curso de formação de mediadores que descreveremos a seguir.

A preocupação com a formação de professores e de mediadores acompanha o projeto desde seu início como projeto temático, em 2006. Essa formação tem sido objeto de pesquisas (ABRAHÃO, 2007; SALOMÃO, 2008; GARCIA, 2011) e, no início do projeto, era viabilizada por meio de reuniões do grupo de pesquisa, eventos sobre o tema e disciplinas em cursos de pós-graduação. No contexto da UNESP-Assis, a grande demanda por mediadores e a necessidade de se discutir as práticas de mediação levou à realização anual de um curso de mediadores.

O curso de formação de mediadores ${ }^{2}$ passou a ser realizado em 2013, a partir da iniciativa de pesquisadores e professores vinculados ao projeto Teletandem. Seu objetivo é formar mediadores, fundamentados pelos resultados das pesquisas sobre Teletandem e telecolaboração. Embora as discussões do curso sejam diretamente relacionadas à compreensão do contexto Teletandem, observamos que seu alcance extrapola esses limites ao propiciar análises profundas sobre como aprendizes de línguas se engajam discursivamente em contato intercultural. Portanto, evidenciamos a necessidade de incorporação dessas discussões também no currículo de cursos de formação de graduação e pós-graduação. Tendo em vista os diversos contextos de comunicação mediados por tecnologias aos quais os aprendizes de línguas têm acesso, a formação de professores precisa considerá-los de modo integrado ao currículo do professor de línguas, não apenas de modo complementar.

\section{Perspectivas de pesquisa}

Na primeira fase do projeto Teletandem Brasil (TELLES, 2006), descrita nas seções anteriores, as pesquisas tinham como foco uma compreensão da configuração do contexto Teletandem. As pesquisas dividiam-se em estudos sobre (a) ferramentas de comunicação utilizadas, (b) a formação de professores e (c) o desenvolvimento

\footnotetext{
${ }^{2}$ Informações sobre o curso disponíveis em: https://mediacaoteletandem.blogspot.com.br
} 
linguístico dos interagentes. Nas páginas ${ }^{3}$ do Teletandem Brasil é possível visualizar todas as publicações do grupo de pesquisa. As primeiras experiências de pesquisa revelaram uma necessidade de aprofundar a compreensão de como as questões culturais permeiam as interações.

As pesquisas da segunda fase do projeto, denominada Teletandem e Transculturalidade (TELLES, 2011), têm priorizado a realização de análises qualitativas, a partir de embasamentos teóricos que abarcam perspectivas discursivas. Nessa etapa tem se priorizado a análise das sessões de interação e das sessões de mediação realizadas nas diferentes modalidades de Teletandem institucional. $\mathrm{O}$ fundamento central dessa fase tem sido o conceito de transculturalidade.

De acordo com Welsch (1999), a abordagem da transculturalidade parte de uma compreensão de cultura como um processo marcado por hibridização, o que leva à constituição de identidades cada vez mais complexas e instáveis. Desse modo, a concepção clássica de culturas como ilhas isoladas, ou monoculturas, é questionada pelo autor.

A concepção essencialista de cultura, originária no século XVIII, segundo Welsch (1999), ainda persiste no cenário político e linguístico das abordagens sobre o tema. Para o autor, essa concepção pode ser caracterizada pelas seguintes perspectivas (a) homogeneização social, por pressupor que comportamentos e identidades individuais e de grupos podem ser unificados dentro de uma única cultura, (b) consolidação étnica, que constitui normativamente os discursos sobre "a cultura de um povo", a partir de características forjadamente inatas (ou socialmente "fabricadas" ou "imaginadas") e (c) delimitação intercultural, que implica na distinção e separação entre culturas, criando sentidos de pertencimento e "do estrangeiro".

Resultados das pesquisas realizadas no escopo do Teletandem e Transculturalidade têm demonstrado de que modos os sujeitos que interagem no contexto Teletandem constroem e negociam sentidos sobre identidades nacionais e sociais. Zakir (2015), por exemplo, ao analisar interações de duplas focais na modalidade de Teletandem institucional semi-integrado, em português e inglês, demonstra como as duplas negociam sentidos sobre o que seja a cultura brasileira e a cultura estrangeira. Segundo a autora, essa negociação se consolida por meio de vozes sociais que evocam discursos de imagens e ideias estereotipadas e sedimentadas sobre a imagem do outro.

Souza (2016), também a partir de uma perspectiva discursiva (FAIRCLOUGH, 2001), analisa a emergência de mal-entendidos em interações de teletandem em contexto institucional semi-integrado em português e inglês. A análise revela limitações nos processos de negociação de mal-entendidos, caracterizados, predominantemente, pelo compartilhamento de informações equivocadas que constituem discursos essencialistas e baseados no senso comum. Embora, no contexto da pesquisa, os malentendidos ocupassem um papel secundário na relação colaborativa entre os pares, sua compreensão e aprofundamento se mostraram uma demanda importante para o contexto da mediação em Teletandem.

\footnotetext{
${ }^{3}$ Páginas do grupo de pesquisa Teletandem Brasil: https://teletandemetransculturalidade.weebly.com/ e http://www.teletandembrasil.org/
} 
Diversos outros estudos foram conduzidos na segunda fase do projeto Teletandem, a partir de $2011^{4}$. A virada focal para a abordagem de fenômenos discursivos tem aberto novos desafios para futuras pesquisas. Dentre os desafios, podemos focalizar (a) a compreensão da mediação como contexto de formação de aprendizes e de professores de línguas e (b) os processos de institucionalização de diferentes modalidades de Teletandem em diversos contextos institucionais.

As experiências de implementação de Teletandem na UNESP, campus de Assis, sinalizam uma demanda crescente por mediadores conscientes do papel formador da aprendizagem colaborativa em Teletandem. A formação esperada nesse contexto tem como objetivo a superação, pelos aprendizes interagentes, do estabelecimento de dicotomias essencialistas baseadas em construções de cultura como uma bolha homogênea. Para tanto, futuras pesquisas devem abrir mão de abordagens de pesquisas pautadas em uma compreensão de língua, aprendizagem, comunicação intercultural integrados a aspectos sociais, políticos e identitários.

Em relação ao segundo desafio, destacamos o crescimento no número de parcerias institucionais realizadas pela UNESP - Assis e universidades no exterior. Um levantamento das parcerias efetivadas entre 2016 e o primeiro semestre de 2017 indica um total de 14 parcerias com universidades norte-americanas, mexicanas, bolivianas e paraguaias. Além delas, também destaca-se, a partir de 2016, a realização de uma parceria com uma universidade britânica, para realização de uma modalidade telecolaborativa em inglês como língua franca.

A crescente procura pelas parcerias viabilizadas pelo grupo Teletandem tem sido atendida tendo em vista as características das demandas de cada contexto. Nesse sentido, as parcerias institucionais semi-integradas (integradas a um curso de línguas e obrigatória para os parceiros no exterior e não integradas e opcionais para os participantes na UNESP - Assis), têm se ajustado a diferentes fatores (disponibilidade de mediadores e laboratórios, horários, requisitos estabelecidos pelos professores e/ou mediadores, por exemplo). Portanto, é fundamental para o desenvolvimento de futuras parcerias a análise das condições e acordos que viabilizam práticas telecolaborativas de aprendizagem como o Teletandem para aprendizes de línguas na UNESP e em instituições parcerias.

\section{Considerações finais}

Ao longo deste artigo buscamos delinear o processo de implementação de contextos telecolaborativos na UNESP - Assis, por meio do projeto Teletandem Brasil. Para tanto, realizamos uma retomada da história do projeto, destacamos seus princípios e perspectivas de pesquisa. Considerando o percurso apresentado neste artigo, consideramos que modalidades telecolaborativas têm ganhado espaço em contextos de ensino e aprendizagem de línguas.

O projeto Teletandem, conforme descrição nas seções deste artigo, insere a UNESP - Assis em uma agenda de iniciativas que contribuem para os processos de internacionalização da instituição. Isso se dá à medida em que estabelece parcerias institucionais com universidades no exterior e que contribui para o desenvolvimento

\footnotetext{
${ }^{4}$ Disponíveis em: http://www.teletandembrasil.org/publications.html
} 
linguístico de aprendizes de línguas de diferentes cursos. Além disso, destacamos também o seu papel na formação de professores para a atuação em contextos telecolaborativos.

Finalizamos, portanto, enfatizando a demanda crescente por modalidades telecolaborativas de aprendizagem. Tal aumento implica a necessidade de mudanças estruturais visando à valorização dos projetos de telecolaboração como contextos de formação. Desse modo, corroboramos com Telles (2009) ao afirmar a relevância de contextos telecolaborativos e multimodais para a superação de barreiras geográficas e promoção de espaços, fazendo com que aprendizes de línguas e professores em formação possam estar em contato com a diversidade social, linguística e cultural de seus parceiros em situações colaborativas de aprendizagem como o Teletandem.

\section{REFERÊNCIAS}

ABRAHÃO, M. H. V. A formação inicial e continuada do professor no Teletandem Brasil: Línguas estrangeiras para todos. Trabalho apresentado na Conferencia Internacional de Educacion a Distancia - Instituto Tecnologico de Monterrey, Mexico, 2007.

BRAMMERTS, H.; CALVERT, M. Learning by communicating in tandem. In: LEWIS, T.; WALKER, L. (Eds.). Autonomous Language Learning In-Tandem. Sheffield, UK: Academy Electronic Publications, 2003. p. 45-60.

CAVALARI, S. M. S.; ARANHA, A. Teletandem: integrating e-learning into the foreign language classroom. Acta Scientiarum: Language and Culture, Maringá, v. 38, n. 4, p. 327-336, 2016.

CANDLIN, C.; HADFIELD, J. Prefácio. In: DUDENEY, G.; HOCKLY, N.; PEGRUM, M. Letramentos digitais. Tradução de M. Marcionilo. São Paulo: Parábola Editorial, 2016.

DOUGHTY, C.; WILLIAMS, J. (Ed.). Focus on form in classroom second language acquisition. Cambridge: Cambridge University Press, 2004.

FAIRCLOUGH, N. Discurso e mudança social. Brasília: Editora Universidade de Brasília, 2001.

FUNO, L. B. A. Teletandem: um estudo sobre identidades culturais e sessões de mediação da aprendizagem. 2015. 190 f. Tese (Doutorado em Estudos Linguísticos) Instituto de Biociências, Letras e Ciências Exatas, Universidade Estadual Paulista "Júlio de Mesquita Filho", São José do Rio Preto, 2015.

GARCIA, D. N. M. O feedback entre diferentes culturas: a perspectiva do exterior. Revista da Anpoll, v. 1, n. 42, p. 96-109, 2017.

Teletandem: Acordos e negociações entre os pares. 2010. 290 f. Tese (Doutorado em Estudos Linguísticos) - Instituto de Biociências, Letras e Ciências Exatas, Universidade Estadual Paulista "Júlio de Mesquita Filho", São José do Rio Preto, 2010.

O professor e a prática telecolaborativa no teletandem. The Especialist (PUCSP), v. 32, n. 1, p. 81-108, 2011. 
LEWIS, M. The lexical approach: The state of ELT and the way forward. Hove, United Kingdom: Language Teaching Publications, 1993.

LITTLE, D. et al. Evaluating tandem language learning by e-mail: report on a bilateral project. CLCS Occasional Paper, Trinity College Dublin, n. 55, p. 1-54, 1999.

SALOMÃO, A. C. B. Gerenciamento e estratégias pedagógicas na mediação dos pares no teletandem e seus reflexos para as práticas pedagógicas dos interagentes. 2008. 317 f. Dissertação (Mestrado em Estudos Linguísticos) - Instituto de Biociências, Letras e Ciências Exatas, Universidade Estadual Paulista "Júlio de Mesquita Filho", São José do Rio Preto, 2008.

SCHWIENHORST, K. Matching pedagogy and technology - Tandem learning and learner autonomy in online virtual language environments. In: SOETAERT, R.; DE MAN, E.; VAN BELLE, E. (Eds.). Language Teaching On-Line. Ghent: University of Ghent, 1998, p. 115-127.

SOUZA, M. G. Teletandem e mal-entendidos na comunicação intercultural online em língua estrangeira. 2016. 170 f. Tese (Doutorado em Estudos Linguísticos) - Instituto de Biociências, Letras e Ciências Exatas, Universidade Estadual Paulista "Júlio de Mesquita Filho", São José do Rio Preto, 2016.

TELLES, J. A. TELETANDEM: Transculturalidade na comunicação online em línguas estrangeiras por webcam. Teletandem News, ano V, n. 1, p. 2-3, jan./abr. 2011.

VASSALlO, M. L.; TELLES, J. A. Aprendendo línguas estrangeiras in-tandem: histórias de identidades. Revista Brasileira de Linguística Aplicada, v. 8, n. 2, p. 341$381,2008$.

Foreign language learning in-tandem: Theoretical principles and research perspectives. The ESPecialist, São Paulo: Educ, v. 27, n. 1, p. 83-118, 2006.

WELSCH, W. Transculturality: the puzzling form of cultures today. In: FEATHERSTONE, M.; LASH, S. Spaces of Culture: City, Nation, World. London: Sage, 1999. p. 194-213.

ZAKIR, M. A. Cultura e $(m)$ telecolaboração: uma análise de parcerias de teletandem institucional. 2015. 232 f. Tese (Doutorado em Estudos Linguísticos) - Instituto de Biociências, Letras e Ciências Exatas, Universidade Estadual Paulista "Júlio de Mesquita Filho", São José do Rio Preto, 2015.

Recebido em: 17/10/2017

Aprovado em: 21/03/2018 